\title{
The Representation of Verbs: Evidence from Syntactic Priming in Language Production
}

\author{
Martin J. Pickering and Holly P. Branigan \\ Human Communication Research Centre, Department of Psychology, University of Glasgow, Glasgow, Scotland
}

\begin{abstract}
We report five experiments that investigate syntactic priming (Bock, 1986b) using a written completion task. Experiments 1 and 2 showed that priming occurs if the prime and target contain different verbs, but that stronger priming occurs if the verb is repeated. Experiment 1 also showed that priming occurs even if the detailed structure of prime and target differ. Experiments 3, 4, and 5 found that priming was unaffected by whether tense, aspect, or number of the verb stayed the same or differed between prime and target. We argue that these results provide evidence about the representation of syntactic information within the lemma stratum. We use these results to extend the model proposed by Roelofs $(1992,1993)$. In particular, we argue that combinatorial information is phrasal in nature, is associated with the verb's lemma rather than a particular form of the verb, and is shared between different lemmas. (1) 1998 Academic Press
\end{abstract}

In this paper, we are concerned with the representation of the syntactic information which underlies the ability to combine lexical entries to form complex structures in language production. There is substantial evidence that semantic and syntactic properties of lexical entries are accessed separately from phonological and morphological properties during language production. This evidence includes tip-of-thetongue phenomena (Brown \& McNeill, 1966; Meyer \& Bock, 1992; Vigliocco, Antonini, \& Garrett, 1997), word-order preferences (Bock, 1986a), speech errors (Dell, 1986; Fromkin, 1971; Garrett, 1975, 1980), aphasic language production (Butterworth, 1989), and picture naming (Levelt et al., 1991; Schriefers, Meyer, \& Levelt, 1990). In light of this evidence, Levelt, Roelofs, and Meyer (in press; cf. Levelt,

The order of authorship is arbitrary. We thank Stuart Boutell, Mike Burton, Andrew Stewart, and three anonymous reviewers and acknowledge Louise McMorris, Emily McIntosh, Ruth McNicol, and Nicola Meechan in assisting with experiments. The research was supported by British Academy Postdoctoral Fellowships (awarded to M.P and H.B.), an EPSRC Research Studentship (awarded to H.B.), and ESRC research grant no. R000237418.

Address reprint requests to Martin Pickering, Human Communication Research Centre, Department of Psychology, University of Glasgow, Florentine House, 53 Hillhead Street, Glasgow G12 8QF, UK. E-mail: martin@psy.gla.ac.uk.
1989) argued that lexical entries include a lemma stratum, encoding syntactic information, and a word-form stratum, encoding morphological and phonological information. (Note that they assume that the lemma stratum does not include semantic information, in contrast to Kempen \& Huijbers, 1983.) Below, we describe a model of the lemma stratum and present five experiments that use syntactic priming (Bock, 1986b) to test this model.

\section{Syntactic Information in the Production \\ Lexicon}

Current linguistic theories assume that lexical entries incorporate syntactic information (e.g., Chomsky, 1981; Pollard \& Sag, 1994). In Levelt et al.'s (in press) terms, such information is stored at the lemma stratum. We identify three types of information which must be represented: (major) category information, featural information, and combinatorial information. Category information encodes the syntactic category of a word (e.g., noun, verb, adjective). Featural information is concerned with, for example, the number, person, tense, and aspect of an instantiation of a verb (and, e.g., the gender, case, and number of an instantiation of a noun). For instance, eats is associated with features which specify it as present tense, perfective aspect, third person, and singular. 
These features must be specified at the lemma stratum in order for the appropriate (morphologically inflected) word-form to be subsequently accessed and retrieved. Combinatorial information specifies the way in which a word can combine with other linguistic units to form possible expressions of the language. A verb (e.g., eat) can combine with arguments (e.g., the men, the food) that correspond to the participants in the action denoted by the verb. Most linguistic theories assume that a verb's representation specifies the types of argument phrase with which it can combine (its subcategorization frame) and the semantic role which each phrase plays in the action denoted by the verb (its thematic grid) (e.g., Jackendoff, 1990). Some linguistic theories further assume that in addition to subcategorization frames specifying possible argument phrases, the lexicon contains combinatorial information about non-argument phrases (e.g., last night in John ate his dinner last night) (e.g., Pollard \& Sag, 1987).

Roelofs (1992, 1993) developed a detailed network model of the representation of nouns and verbs in production which included some syntactic information (see also Jescheniak \& Levelt, 1994; Levelt et al., in press; Schriefers et al., 1990). In Roelofs' model, the lemma stratum contains lemma nodes (one for each lexical concept) which are connected to nodes at both the conceptual stratum (where messages are generated) and the word-form stratum (where morphology and phonology are specified). For example, in Dutch the lemma hond ("dog") is linked to the concept DOG at the conceptual stratum and the word-forms hond (singular) and honden (plural) at the word-form stratum. The lemma stratum also contains syntactic property nodes, which are connected to the lemma nodes via labeled links, such as SYNTACTIC_CATEGORY. In Roelofs' model of noun representation, each syntactic category is represented by a single node. Thus, hond and dier ("animal") are both linked to the $\mathrm{N}$ node. Syntactic gender information is also represented at the lemma stratum. This assumption is supported by Vigliocco et al.'s (1997) finding that Italian speakers can be aware of syntactic gender while in a tip-of-the-tongue state (see also Badecker, Miozzo, \& Zanuttini, 1995; though cf. Miozzo \& Caramazza, 1997). In Roelofs' model, each gender is represented by a single node. The lemma hond is masculine and hence links to the masculine node; the lemma dier is neuter and hence links to the neuter node.

We now propose an extension of Roelofs' $(1992,1993)$ model of the lemma stratum to incorporate syntactic aspects of verb representation (see Fig. 1). We assume a network of lemma nodes corresponding roughly to the base form of a word (e.g., for $d o g$ or eat) connected via labeled links to nodes that represent the words' syntactic properties. Roelofs' model included category and gender nodes. We extend this to include nodes representing other features and nodes representing combinatorial information.

Roelofs (1992) assumed a single node for each category (e.g., noun) or feature (e.g., masculine). Hence, the lemmas corresponding to different words of the same category or sharing a feature are linked to the same category or feature node. We assume that, in sentence production, whenever the lemma hond is activated, the noun node and the masculine node are also activated, because hond is a masculine noun. We assume that the links between the lemma node and the category and feature nodes are also activated; but for simplicity, our discussion will be in terms of node activation. Similarly, whenever the lemma give is activated in Fig. 1, the verb node is activated. We say that these nodes are inherently activated whenever the lemma is activated.

Not all nodes are inherently activated. The lemma give is linked to both the past tense node and the present tense node. When the word gave is used, the past tense node is activated along with the lemma give. But when the word gives is used, the present tense node is activated instead. The same holds for the aspect nodes and the number nodes. (Similarly, the lemma hond will be linked to both a singular node and a plural node; and only one of these will be activated along with hond.) Figure 1 shows that all of these feature nodes are linked to the verb lemmas.

We also assume the existence of combinatorial nodes, which are activated when a verb is used in a particular construction. For instance, 


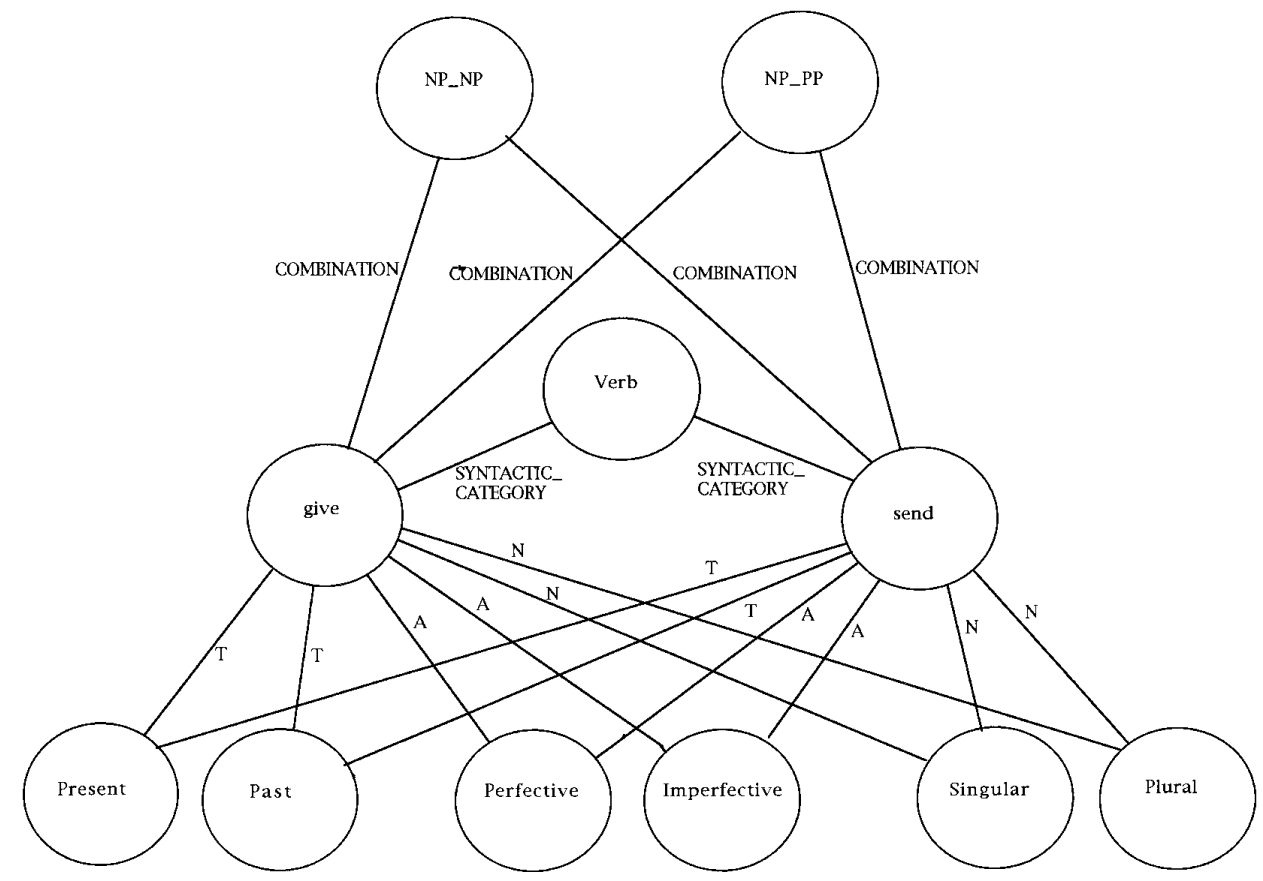

FIG. 1. A partial model of the representation of syntactic information associated with verbs in the production lexicon. The labels $\mathrm{T}, \mathrm{A}$, and $\mathrm{N}$ refer to tense, aspect, and number, respectively.

the verb give is used in (at least) two different constructions: with two noun phrases, as in give the $\operatorname{dog}$ a bone; or with a noun phrase and a prepositional phrase, as in give a bone to the dog. We call these the double object $(D O)$ and prepositional object $(\mathrm{PO})$ constructions respectively. For now, we make the following assumptions: Using the verb give in the DO construction involves activating the $N P, N P$ node; using it in the PO construction involves activating the $N P, P P$ node. (Note that the connection between the lemma node and the combinatorial nodes might be mediated by nodes specifying grammatical functions like subject and direct object [e.g., Levelt, 1989; cf. Garrett, 1975].) In keeping with the discussion above, we leave it open whether the combinatorial nodes encode give's subcategorisation frames or its overall combinatorial potential (i.e., with respect to both argument and non-argument phrases) (see General Discussion). Finally, we assume that all of the category, feature, and combinatorial nodes link directly to, and only to, the lemma nodes. This means, for example, that combinatorial information is represented as a property of a verb lemma, not as a property of a particular instantiation of a verb.

\section{Syntactic Priming}

We suggest that this model can be investigated using syntactic priming (Bock, 1986b). This paradigm is based on the finding that language users have a tendency to repeat syntactic structure. Studies of corpora have reported tendencies toward repetition in natural dialogue at many levels (Estival, 1985; Giles \& Powesland, 1975; Schenkein, 1980; Tannen, 1989; Weiner \& Labov, 1983). Syntactic repetition may have many causes (e.g., lexical priming or discourse register). However, Bock (Bock, 1986b, 1989; Bock \& Loebell, 1990; Bock, Loebell \& Morey, 1992; cf. Branigan, Pickering, Liversedge, Stewart, \& Urbach, 1995; Potter \& Lombardi, 1998) found experimental evidence that it may sometimes arise from the repetition of processes responsible for building syntactic structure during language production. She termed this syntactic priming. Under the guise of a memory test, 
Bock (1986b) presented participants with PO priming sentences like (4a) and DO priming sentences like (4b):

4a. The rock star sold some cocaine to an undercover agent.

4b. The rock star sold an undercover agent some cocaine.

After repeating one of these sentences, the participants saw a picture which could be described using either a $\mathrm{PO}$ or a DO construction. For example, the picture might show a girl handing a paintbrush to a man. The prime was not semantically related to the target picture, and the prime and target did not form a connected discourse. The form of the priming sentence affected the form of the description. Participants tended to produce a PO form like The girl handed a paintbrush to the man after a $\mathrm{PO}$ prime, and a DO form like The girl handed the man a paintbrush after a DO prime. Bock (1986b) also found priming effects with active and passive sentences.

Bock (1989) found priming for PO sentences even when prime and target involved different prepositions: The secretary baked a cake for her boss was as effective as The secretary took a cake to her boss in eliciting The girl handed the paintbrush to the man. Bock and Loebell (1990) found that sentences containing locative prepositional phrases (e.g., The wealthy widow drove her Mercedes to the church) primed PO descriptions when the prepositional phrase was not a locative (e.g., 4a). Additionally, sentences containing a locative by-phrase like The foreigner was loitering by the broken traffic light primed passive descriptions involving an agentive byphrase. Furthermore, Susan brought a book to study did not prime The girl gave a brush to the man, despite their prosodic similarities. Taken together, these results suggest that syntactic priming cannot be explained by lexical, thematic, or metrical correspondences between prime and target.

We hypothesise that syntactic priming can be explained in terms of activation at the lemma stratum. We assume that production of a word involves activation of the associated nodes at the lemma stratum. For example, when a speaker produces The man gives the dog a bone, the word gives involves activation of the lemma give, the feature nodes for third person, singular, present tense, and so on, and the combinatorial node $N P, N P$. Activation of these nodes (and the links between them) gradually decays, but does not disappear immediately. These nodes are therefore at an advantage in the production of a subsequent sentence. Thus if the speaker subsequently wishes to convey the message that a woman gives a present to a boy, the combinatorial node $N P, N P$ (and the link between it and the give lemma node) will be more highly activated than normal, and hence that combinatorial frame is more likely to be selected. Therefore the speaker is more likely than normal to produce a sentence with a DO structure like $A$ woman gives a boy a present.

According to the model in Fig. 1, the combinatorial nodes $N P, N P$ and $N P, P P$ are directly linked to the lemma give, which is unspecified for features like tense, aspect, or number. Therefore we predict that syntactic priming will occur between two instances of a verb, regardless of whether the instances involve different features, and, moreover, that the magnitude of priming will not vary.

Additionally, the combinatorial nodes are shared between different lemmas (e.g., give and send). Hence we predict some priming between verbs: Prior activation of a combinatorial node (e.g., $N P, P P$ ), together with a lemma node (e.g., give), should affect its likelihood of being activated in combination with any other lemma node linked to it. However, we also predict that priming between verbs will be weaker than priming between two instances of the same verb. This is because the use of a particular verb as part of a given structure will activate the verb node, the relevant combinatorial node, and the link between them. If the same verb is used again, then residual activation of both the combinatorial node and the link will favor selection of the same combinatorial node. But if a different verb linked to the same combinatorial node is used instead, only the residual activation of the combinatorial node can be the cause of priming.

To summarize, this model predicts strong priming when the same verb appears in consec- 
utive sentences. Varying the verb between prime and target should reduce but not eliminate the priming effect. Varying the form of a particular verb should not affect priming. We now report five syntactic priming experiments that tested these predictions using a written completion task. Experiment 1 contrasted conditions in which prime and target used the same verb with conditions in which the verb varied. Experiment 2 concentrated on cases where the verb varied and used two prime fragments. Experiments 3, 4, and 5 varied features of a verb: tense in Experiment 3, aspect in Experiment 4, and number in Experiment 5.

\section{EXPERIMENT 1}

\section{Participants}

Thirty-six participants from the University of Glasgow community were paid to participate.

\section{Items}

We constructed 32 sets of items. Each comprised two sentence fragments (see Appendix):

1a. The racing driver showed the torn overall...

1b. The racing driver showed the helpful mechanic ...

1c. The racing driver gave the torn overall ...

1d. The racing driver gave the helpful mechanic...

2. The patient showed...

The first fragment $(1 \mathrm{a}-\mathrm{d})$ was the prime; the second fragment (2) was the target. Every fragment contained a subject noun phrase followed by a verb that could appear with the PO or the DO construction. The prime fragment also contained a postverbal noun phrase, comprising a determiner followed by a noun, a noun compound, or an adjective and a noun. This phrase always had the same syntactic structure across conditions within an item set.

Hence every prime fragment could be completed as either a PO or a DO construction. However, we manipulated the postverbal noun phrase in the prime fragment to induce PO or DO completions. In (1a and c), the postverbal noun phrase is a plausible patient but an implausible beneficiary for the action denoted by the verb. Participants should therefore be likely to complete these fragments using the PO con- struction, where the postverbal noun phrase is the patient of the verb (e.g., The racing driver showed/gave the torn overall to the team manager). In contrast, the postverbal noun phrase in ( $1 \mathrm{~b}$ and $\mathrm{d})$ is a plausible beneficiary but an implausible patient. Participants should therefore be likely to complete these fragments using the DO construction, where the postverbal noun phrase is the beneficiary of the verb (e.g., The racing driver showed/gave the helpful mechanic the damaged tyre).

We manipulated the verb in the prime fragments, so that in (1a and b), it was the same as the verb in the target fragment, but in (1c and d), it differed. The experimental items employed nine verbs (see Appendix). Previous experiments showed that participants were likely to produce both PO and DO completions for these verbs, without producing a high proportion of other constructions.

The experimental items were placed into four lists, each comprising eight items from each condition, such that one version of each item appeared in each list. In addition, we constructed 160 filler fragments. Out of these, 112 were noun phrases of varying types (including some containing verbs in embedded clauses), 24 were noun phrases followed by a verb, and 24 were noun phrases followed by a verb and a noun phrase. None of the filler fragments contained a verb which could be completed with a PO or DO construction. Some verbs appeared in more than one filler fragment.

We constructed 36 thirteen-page booklets of 224 fragments, consisting of 64 experimental fragments (i.e., 32 items), together with the 160 filler fragments. Each page (except the last page) contained 18 fragments. The order of fragments was individually randomized for each booklet, with the constraint that at least four filler fragments intervened between experimental items (except at the end of booklets, where occasionally items were more closely spaced).

Instructions on the front page of the booklet explained that we were interested in seeing what sorts of sentences people produce, and that participants should complete the fragments in any way that they liked, ensuring they produced a 
grammatical sentence. The instructions stressed completing each fragment as quickly as possible, with the first completion that came to mind. Participants were told to fill in the booklet in order, without leaving out any fragments.

\section{Procedure}

Participants were each given a booklet to complete, and were told to hand it back to the experimenter when they were finished. The experimenter answered any questions that the participants had. The experiment took about $30 \mathrm{~min}$.

\section{Scoring}

For each experimental fragment, the first legible response made by the participant was scored as a PO, a DO, or Other. Prime completions were scored as POs if the completion contained a beneficiary noun phrase which was the object of the preposition to and as DOs if the completion contained a patient (or theme) noun phrase. To be scored as either a PO or a DO completion, the verb provided in the fragment could not form part of a phrasal verb (e.g., The architect handed the latest plan over to the builder). All other prime completions were scored as Others. Note that scoring was based on participants' actual completions. For example, if a participant completed a DO-inducing prime fragment as a PO (e.g., completing The mother gave the baby with to her husband), the completion was scored as a PO.

Target completions were scored as POs if the verb provided in the fragment was immediately followed by a noun phrase which acted as the patient or theme and then by a prepositional phrase beginning with to, which acted as the beneficiary. Target completions were scored as DOs if the verb was immediately followed by a noun phrase which acted as the beneficiary and then by a noun phrase which acted as the patient (or theme). To be scored in either category, a completion had to have a grammatical alternative in the other category, where the order of the patient and beneficiary was reversed. Additionally, the verb provided in the fragment could not form part of a phrasal verb. All other target completions were scored as Others.

\section{Design and Data Analysis}

Every participant completed 32 target fragments, eight in each of the four priming conditions defined by the combination of the Verb factor (same vs different verb, in prime and target fragments) and the Prime Completion factor (PO prime completion vs DO prime completion). Every experimental item was presented to all 36 participants, with 9 participants seeing any one version of an item.

Our dependent variables were the proportions of PO and DO target responses following PO prime completions, and the proportions of $\mathrm{PO}$ and DO target responses following DO prime completions. In other words, we computed the conditional probabilities of PO target completions following PO prime completions, DO target completions following PO prime completions, and so on. For example, we divided the total number of PO target completions following a PO prime completion by the sum of PO, $\mathrm{DO}$, and Other target completions following a PO prime. By calculating the dependent variables in this way, we allowed for the possibility that different prime completions might differentially affect the combined proportion of $\mathrm{PO}$ and DO target completions. We did not compare absolute numbers of PO and DO target completions, because participants could complete the prime fragments in any way that they wished, and so the total number of completions following each type of prime might not have been the same.

For each condition, we computed the relevant proportions by dividing the number of target completions in the PO and DO categories by the total number of target completions in that condition. These proportions were calculated for each participant and for each item. Target Completion (PO target completion vs DO target completion) therefore constituted an additional factor. Analyses of variance were performed on these data, with separate analyses treating participants and items as random effects.

\section{Results}

Application of the scoring criteria yielded 1042 trials where the prime fragment was com- 
TABLE 1

Experiment 1 Results

Target

completion

\begin{tabular}{lccc}
\cline { 3 - 3 } Verb type & $\begin{array}{c}\text { Prime } \\
\text { completion }\end{array}$ & PO & DO \\
\hline \multirow{2}{*}{ Same } & PO & .47 & .22 \\
& DO & .29 & .38 \\
Different & PO & .40 & .25 \\
& DO & .35 & .29 \\
\hline
\end{tabular}

Note. PO, prepositional object; DO, double object.

pleted as either a PO or as a DO $(90 \%$ of all responses). Twenty-four percent of these were completed as same verb-PO primes, $26 \%$ as same verb-DO primes, $23 \%$ as different verb-PO primes, and $27 \%$ as different verb-DO primes. In these 1042 trials, participants produced 390 (37\%) PO completions, 303 (29\%) DO completions, and 349 (34\%) Other completions for the target fragment. The combined proportion of $\mathrm{PO}$ and DO target completions was comparable in each condition: $69 \%$ following same verb-PO primes, $68 \%$ following same verb-DO primes, $67 \%$ following different verb-PO primes, and $63 \%$ following different verb-DO primes. Hence the priming manipulation did not affect the combined proportion of PO and DO target completions (all $F \mathrm{~s}<2$ ). However, it did affect the relative proportions of these two types of completion, as we discuss below. Table 1 shows the proportions of $\mathrm{PO}$ and DO responses in the four experimental conditions. Three-way analyses of variance revealed an interaction of Prime Completion and Target Completion $\left(F_{1}(1,35)=22.74, p<.01, M S_{\mathrm{e}}=.037\right.$; $\left.F_{2}(1,31)=27.70, p<.01, M S_{\mathrm{e}}=.047\right)$. An examination of Table 1 shows that participants produced more target completions that were of the same type (PO or DO) as the prime completions than target completions that were of the alternative type to the prime completions.

We employed simple effects to test the hypotheses that participants would produce more PO target completions following PO prime completions than following DO prime completions, and more DO target completions follow- ing DO prime completions than following PO prime completions. Both of these hypotheses were supported (all $p \mathrm{~s}<.01$ ).

The analyses of variance also revealed a three-way interaction of Prime Completion, Target Completion, and Verb $\left(F_{1}(1,35)=5.65\right.$, $p<.05, M S_{\mathrm{e}}=.052 ; F_{2}(1,31)=7.62, p<.01$, $\left.M S_{\mathrm{e}}=.024\right)$. Table 1 shows that the interaction between Prime Completion and Target Completion was more marked when prime and target contained the same verb than when they contained different verbs.

In order to explore this effect further, we conducted two-way analyses of variance separately for the two levels of the Verb factor. When prime and target contained the same verb, there was a strong preference for producing target completions of the same type as prime completions $\left(F_{1}(1,35)=23.49, p<.01, M S_{\mathrm{e}}=\right.$ $\left..045 ; F_{2}(1,31)=40.84, p<.01, M S_{\mathrm{e}}=.030\right)$. When the verb varied, this preference was unreliable on the participants' analysis $\left(F_{1}(1,35)\right.$ $=1.57, p<.22, M S_{\mathrm{e}}=.044 ; F_{2}(1,31)=6.13$, $\left.p<.05, M S_{\mathrm{e}}=.041\right)$.

Finally, the main analyses revealed a weak tendency for participants to produce more PO than DO target completions, significant by participants only $\left(F_{1}(1,35)=4.39, p<.05, M S_{\mathrm{e}}=\right.$ $\left..15 ; F_{2}(1,31)=2.98, p<.10, M S_{\mathrm{e}}=.19\right)$. No other effects approached significance.

We also investigated whether priming occurred when the prime and target completions differed in detailed syntactic structure. To do this, we rescored the PO and DO target responses as follows. For responses where the prime and target completions were of the same type, we examined only responses where the constituent structure of at least one of the postverbal noun phrases differed between prime and target completions. For example, we would include the prime-target pair The racing driver showed the torn overall to the manager and The patient showed his spots to the doctor, because the torn overall and his spots differ in constituent structure. For responses where the prime and the target completions were of different types, we converted the target response to its alternative form (e.g., converting The patient showed the doctor his spots to The patient 
showed his spots to the doctor) and then employed the same criterion. We made standard syntactic assumptions, for example distinguishing between adjective-noun sequences and noun-noun compounds, but treating possessives and determiners as a single category. This procedure excluded a further 110 responses $(10.6 \%$ of target completions following PO and DO prime completions). Note that this procedure does not exclude any cases where participants substantially repeated words between prime and target without exact structure repetition (see Experiment 3). Analyses conducted on the rescored data produced an identical pattern of results to the main analyses.

\section{Discussion}

These results demonstrate that the structure of participants' target completions was affected by the structure of their immediately preceding completions. Participants produced $11.7 \%$ more PO target completions following PO prime completions than following DO prime completions, and 9.8\% more DO target completions following DO prime completions than following PO prime completions. This tendency to repeat structure between sentences was greater when both sentences contained the same verb than when the verb differed. When the sentences contained the same verb, participants produced $17.2 \%$ more target completions that were of the same type as the prime completions than target completions that were of the alternative type to the prime completions. This dropped to $4.4 \%$ when the sentences contained different verbs. The findings remained similar when we excluded trials on which the prime and target completions had identical constituent structures.

We argue that these results provide evidence for syntactic priming during written language production in the context of a sentence-completion task. They also show that syntactic priming is not dependent on exact repetition of structure between prime and target. Most interestingly, they demonstrate that syntactic priming is affected by whether the verb is repeated between prime and target. Whereas a strong priming effect occurred when the verb was repeated, the effect when the verb differed was significantly reduced and was in fact unreliable on the participants' analysis. This contrasts with previous research which found reliable priming between sentences in which the verb was very unlikely to have been repeated (e.g., Bock, 1986b). In order to be confident that our technique was sensitive to priming when the verb was not repeated, we conducted a second experiment in which the target was preceded by the potentially stronger context of two primes.

\section{EXPERIMENT 2}

\section{Participants}

Sixty-four participants from the University of Glasgow community were paid to participate.

\section{Items}

We constructed 12 sets of items. Each comprised three sentence fragments (see Appendix):

3a. The pub offered a free beer...

$3 b$. The pub offered the loyal customers...

4a. The American penpal mailed a scenic postcard ...

4b. The American penpal mailed the Greek woman...

5. The injured climber showed...

Fragments $(3 a-b)$ and $(4 a-b)$ were the primes; fragment (5) was the target. Each fragment contained a subject noun phrase followed by a verb that could appear in either the PO or the DO construction and a postverbal noun phrase. We manipulated this noun phrase to favor the $\mathrm{PO}$ construction in (3a) and (4a) and the DO construction in (3b) and (4b), just as in Experiment 1. Each of the three fragments in an item contained a different verb.

The experiment had two conditions: Either both of the primes in an item favored a PO completion [as in (3a) and (4a)] or both favored a DO completion [as in (3b) and (4b)]. The items were placed into two lists, each comprising six items from each condition, so that one version of each item appeared in each list. In addition, we constructed 72 filler fragments. Out of these, 60 were noun phrases of various types (including some containing verbs in embedded clauses) and 12 were noun phrases followed by a verb. None of the filler fragments 
contained a verb which could be completed with a PO or a DO construction.

We constructed 64 six-page booklets of 108 fragments, consisting of 36 experimental fragments (12 items) and 72 filler fragments. The order of fragments was individually randomized, with the constraint that at least three filler fragments intervened between experimental items (except at the end of booklets). Instructions and format were the same as in Experiment 1.

\section{Procedure, Scoring, and Design and Data}

Analysis

Procedure and scoring were the same as in Experiment 1. The experiment took about 20 min to complete. Every participant completed 12 target fragments, 6 in each of the two priming conditions defined by the Prime Completion factor (PO prime vs DO prime). The other factor was Target Completion (PO target vs DO target). Every experimental item was presented to 64 participants, with 32 participants seeing any one version of an item. Our dependent variables were the proportions of PO and DO target completions, calculated as in Experiment 1. We only considered target completions for trials in which both primes were completed as POs or both primes were completed as DOs.

\section{Results and Discussion}

Application of the scoring criteria yielded 534 trials where the prime fragments were both completed as POs or both as DOs (70\% of all responses). Forty-three percent of these were completed as PO primes, and 57\% were completed as DO primes. In these 534 trials, participants produced 203 (38\%) PO completions, 181 (34\%) DO completions, and 150 (28\%) Other completions for the target fragment. The combined proportion of PO and DO target responses was $72 \%$ following PO primes and $72 \%$ following DO primes. Hence the priming manipulation did not affect the overall proportion of PO and DO target completions (both $F \mathrm{~s}<1$ ).

Table 2 shows the proportions of PO and DO completions in the two experimental conditions. Analyses of variance revealed an interaction of Prime Completion and Target Completion $\left(F_{1}(1,63)=31.68, p<.01, M S_{\mathrm{e}}=.073\right.$;
TABLE 2

Experiment 2 Results

\begin{tabular}{cll}
\hline & \multicolumn{2}{l}{ Target completion } \\
\cline { 2 - 3 } Prime completion & PO & DO \\
\hline PO & .52 & .21 \\
DO & .32 & .38 \\
\hline
\end{tabular}

Note. PO, prepositional object; DO, double object.

$\left.F_{2}(1,11)=23.75, p<.01, M S_{\mathrm{e}}=.017\right)$. An examination of Table 2 shows that participants produced more target completions that were of the same type (PO or DO) as the prime completions than target completions that were of the alternative type to the prime completions.

Tests for simple effects demonstrated that participants produced more PO target completions following PO primes than following DO primes, and more DO target completions following DO primes than following PO primes (all $p \mathrm{~s}<.01$ ). Finally, the main analyses revealed a weak tendency for participants to produce more PO than DO target completions, significant by participants only $\left(F_{1}(1,63)=6.03\right.$, $\left.p<.05, M S_{\mathrm{e}}=.16 ; F_{2}(1,11)<1\right)$. No other effects approached significance.

These results demonstrate that syntactic priming occurs in written production between sentences that do not share the same verb. Participants produced $20.3 \%$ more PO target completions following PO prime completions than following DO prime completions, and 17.7\% more DO target completions following DO prime completions than following PO prime completions. Putting Experiments 1 and 2 together, we suggest that syntactic priming occurs whether the verb is repeated or not, but that stronger syntactic priming occurs if the verb is repeated.

\section{EXPERIMENT 3}

\section{Participants}

Thirty-six participants from the University of Glasgow community participated as volunteers. 
Items

We constructed 32 sets of items. Each comprised two sentence fragments (see Appendix):

6a. The racing driver showed the torn overall...

$6 \mathrm{~b}$. The racing driver showed the helpful mechanic ...

6c. The racing driver shows the torn overall ...

$6 \mathrm{~d}$. The racing driver shows the helpful mechanic ...

7. The patient showed...

The items were based on those in Experiment 1, but items that produced high proportions of Other completions in either prime or target were modified. Fragments $(6 a-d)$ were the prime fragments; and fragment (7) was the target fragment. In this experiment, the prime and target fragments always contained the same verb. Instead, the tense of the verb was manipulated. In ( $6 a$ and $b)$, the prime fragment contained a past tense verb. In (6c and $\mathrm{d}$ ), the prime fragment contained a present tense verb. The target was always in the past tense. We also constructed 128 fillers, half of them present tense and half of them past tense. Half of the fillers in each tense comprised a subject noun phrase followed by a verb; the remaining half comprised a subject noun phrase, verb, and postverbal noun phrase. We constructed 36 individually randomized eleven-page booklets of 192 fragments in which experimental trials were separated by at least three filler trials. The format of the booklets and the instructions were the same as in Experiment 1.

\section{Procedure, Scoring, and Design and Data Analysis}

These were the same as in Experiment 1, except that the factors were Tense (same tense vs different tense, in prime and target fragments), Prime Completion (PO prime vs DO prime), and Target Completion (PO target vs DO target).

\section{Results and Discussion}

Application of the scoring criteria yielded 1016 trials where the prime fragment was completed as either a PO or as a DO (88\% of all responses). Twenty-two percent of these were completed as same tense-PO primes, $28 \%$ as same tense-DO primes, $23 \%$ as different tense-PO primes, and $27 \%$ as different tense-DO primes. In these 1016
TABLE 3

Experiment 3 Results

\begin{tabular}{lccc}
\hline & & \multicolumn{2}{c}{$\begin{array}{c}\text { Target } \\
\text { completion }\end{array}$} \\
\cline { 3 - 4 } Tense & $\begin{array}{c}\text { Prime } \\
\text { completion }\end{array}$ & PO & DO \\
\hline \multirow{2}{*}{ Same } & PO & .50 & .19 \\
Different & DO & .34 & .32 \\
& PO & .44 & .23 \\
& DO & .32 & .34 \\
\hline
\end{tabular}

Note. PO, prepositional object; DO, double object.

trials, participants produced 404 (40\%) PO completions, 281 (28\%) DO completions, and 331 (33\%) Other completions for the target fragment. The combined proportion of PO and DO target completions was comparable in each condition: $71 \%$ following same tense-PO primes, $65 \%$ following same tense-DO primes, $69 \%$ following different tense-PO primes, and $65 \%$ following different tense-DO primes. Analyses by items suggested that participants produced more Other completions after a DO prime than after a PO prime, but analyses by participants did not $\left(F_{1}(1,35)<1 ; F_{2}(1,31)=4.45, p<.05, M S_{\mathrm{e}}=\right.$ $.015)$. There were no other differences for Other completions (all $F$ s $<1$ ).

Table 3 shows the proportions of PO and DO responses in the four experimental conditions. Three-way analyses of variance revealed a main effect of Target Completion $\left(F_{1}(1,35)=5.11\right.$, $p<.05, M S_{\mathrm{e}}=.23 ; F_{2}(1,31)=8.09, p<.01$, $\left.M S_{\mathrm{e}}=.15\right)$, and an interaction of Prime Completion and Target Completion $\left(F_{1}(1,35)=24.99\right.$, $p<.01, M S_{\mathrm{e}}=.049 ; F_{2}(1,31)=14.56, p<.01$, $\left.M S_{\mathrm{e}}=.077\right)$. Table 3 shows that participants produced more target completions that were of the same type (PO or DO) as the prime completions than target completions that were of the alternative type to the prime completions. Simple effects (based on the two-way interaction) demonstrated that participants produced more PO target completions following PO primes than following DO primes and more DO target completions following DO primes than following PO primes (all $p$ s $<$ .05). No further effects approached significance. In particular, there was no three-way interaction of 
Prime Completion, Target Completion, and Tense $(F \mathrm{~s}<1)$. Analyses conducted over each level of the Tense factor revealed that a syntactic priming effect occurred in both the same tense conditions $\left(F_{1}(1,35)=16.15, p<.01, M S_{\mathrm{e}}=.046 ; F_{2}(1,31)\right.$ $\left.=14.66, p<.01, M S_{\mathrm{e}}=.048\right)$ and the different tense conditions $\left(F_{1}(1,35)=11.76, p<.01, M S_{\mathrm{e}}\right.$ $\left.=.041 ; F_{2}(1,31)=7.70, p<.01, M S_{\mathrm{e}}=.056\right)$.

To rule out the possibility that apparent priming might in fact be due to participants' reusing all or part of the prime completion in the target completion, we rescored the data to exclude all trials on which the prime and target completions shared any open-class word or pronoun. This excluded 44 further trials (4.3\% of scoreable responses). Analyses conducted on the rescored data produced an identical pattern of results to the main analyses.

Experiment 3 demonstrated that syntactic priming occurred when tense differed between prime and target, as well as when it stayed the same, and suggested that it was unaffected by differences in tense between prime and target. This contrasts with the findings of Experiment 1 , which showed that changing the verb between prime and target did affect syntactic priming.

\section{EXPERIMENT 4}

\section{Participants}

Twenty-four participants from the University of Glasgow community participated as volunteers.

\section{Items}

We constructed 32 sets of items. Each comprised two sentence fragments (see Appendix A):

8a. The racing driver showed the torn overall ...

8 b. The racing driver showed the helpful mechanic ...

$8 \mathrm{c}$. The racing driver was showing the torn overall ...

$8 \mathrm{~d}$. The racing driver was showing the helpful mechanic ...

9. The patient showed ...

Fragments $(8 \mathrm{a}-\mathrm{d})$ were the prime fragments; and fragment (9) was the target fragment. The prime and target fragment always contained the same verb, but the aspect of the verb was manipulated. In ( $8 \mathrm{a}$ and $\mathrm{b})$, the prime fragment contained a perfective aspect verb. In ( $8 \mathrm{c}$ and $\mathrm{d}$ ), the prime fragment contained an imperfective aspect verb; note that in these conditions, the verb was realized as two words. The target was always perfective aspect. In other respects, the items were identical to those in Experiment 3. We constructed 128 fillers similar to those in Experiment 3, but counterbalanced for aspect instead of tense. Otherwise the booklets were identical to Experiment 3.

\section{Procedure, Scoring, and Design and Data Analysis}

These were the same as in Experiment 1, except that the factors were Aspect (same aspect vs different aspect, in prime and target fragments), Prime Completion (PO prime vs DO prime), and Target Completion (PO target vs DO target).

\section{Results and Discussion}

Application of the scoring criteria yielded 663 trials where the prime fragment was completed as either a PO or as a DO (86\% of all responses). Twenty-four percent of these were completed as same aspect-PO primes, $27 \%$ as same aspect-DO primes, $22 \%$ as different aspect-PO primes, and $27 \%$ as different aspect-DO primes. In these 663 trials, participants produced 256 (39\%) PO completions, 206 (31\%) DO completions, and 201 (30\%) Other completions for the target fragment. The combined proportion of PO and DO target completions was comparable in each condition: $75 \%$ following same aspect-PO primes, $69 \%$ following same aspect-DO primes, $69 \%$ following different aspect-PO primes and $66 \%$ following different aspect-DO primes. The priming manipulation did not affect the overall proportion of $\mathrm{PO}$ and DO target completions (all $F \mathrm{~s}<2.1$ ).

Table 4 shows the proportions of PO and DO completions in the four experimental conditions. Three-way analyses of variance revealed an interaction of Prime Completion and Target Completion $\left(F_{1}(1,23)=28.04, p<.01, M S_{\mathrm{e}}=\right.$ $\left..052 ; F_{2}(1,31)=22.83, p<.01, M S_{\mathrm{e}}=.062\right)$. Table 4 shows that participants produced more target completions that were of the same type (PO or DO) as the prime completions than target completions than were of the alternative type to the prime completions. Simple effects (based on the two-way interaction) demon- 
TABLE 4

Experiment 4 Results

\begin{tabular}{lccc}
\hline & & \multicolumn{2}{c}{$\begin{array}{c}\text { Target } \\
\text { completion }\end{array}$} \\
\cline { 3 - 4 } Aspect & $\begin{array}{c}\text { Prime } \\
\text { completion }\end{array}$ & PO & DO \\
\hline Same & PO & .51 & .24 \\
& DO & .35 & .34 \\
Different & PO & .48 & .22 \\
& DO & .24 & .42 \\
\hline
\end{tabular}

Note. PO, prepositional object; DO, double object.

strated that participants produced more PO target completions following PO primes than following DO primes, and more DO target completions following DO primes than following PO primes (all $p \mathrm{~s}<.01$ ).

Table 4 suggests that there may be a stronger priming effect in the different aspect conditions than the same aspect conditions, contrary to the predicted effect if priming were magnified by the repetition of aspect. The three-way interaction of Prime Completion, Target Completion, and Aspect approached significance by items, but not by participants $\left(F_{1}(1,23)=1.64, p=.21, M S_{\mathrm{e}}=\right.$ $\left..054 ; F_{2}(1,31)=3.70, p<.07, M S_{\mathrm{e}}=.058\right)$. Analyses conducted over each level of the Aspect factor revealed that a syntactic priming effect occurred in both the same aspect conditions $\left(F_{1}(1,23)=7.17, p<.01, M S_{\mathrm{e}}=.058 ; F_{2}(1,31)\right.$ $\left.=3.61, p<.07, M S_{\mathrm{e}}=.073\right)$ and the different aspect conditions $\left(F_{1}(1,23)=23.80, p<.01, M S_{\mathrm{e}}\right.$ $\left.=.048 ; F_{2}(1,31)=29.30, p<.01, M S_{\mathrm{e}}=.047\right)$. Hence Experiment 4 demonstrated that syntactic priming occurred when aspect differed between prime and target, as well as when it stayed the same, and suggested that it was unaffected by differences in aspect between prime and target. It also demonstrated that priming is unaffected by variations in the internal constituent structure of the verb.

\section{EXPERIMENT 5}

\section{Participants}

Twenty-eight participants from the University of Glasgow community were paid to participate.
Items

We constructed 32 sets of items. Each comprised two sentence fragments (see Appendix):

10a. The racing driver shows the torn overall ...

10b. The racing driver shows the helpful mechanic ..

10c. The racing drivers show the torn overall ...

10d. The racing drivers show the helpful mechanic ...

11. The patient shows...

The items were based on those in Experiment 3, but items that produced high proportions of Other completions in either prime or target were modified. Fragments $(10 \mathrm{a}-\mathrm{d})$ were the prime fragments; and fragment (11) was the target fragment. The prime and target fragment always contained the same verb, but the number of the verb was manipulated. In (10a and b), the prime fragment contained a singular verb. In (10c and d), the prime fragment contained a plural verb. The target was always singular. We constructed 128 fillers based on those in Experiment 3, but counterbalanced for number instead of tense. All of the fragments in the experiment were in the present tense, so that number was overtly marked in the morphology of the verb. Otherwise the booklets were identical to Experiment 3.

\section{Procedure, Scoring, and Design and Data} Analysis

These were the same as in Experiment 1, except that the factors were Number (same aspect vs different aspect, in prime and target fragments), Prime Completion (PO prime vs DO prime), and Target Completion (PO target vs DO target).

\section{Results and Discussion}

Application of the scoring criteria yielded 793 trials where the prime fragment was completed as either a PO or as a DO (89\% of all responses). Twenty-two percent of these were completed as same number-PO primes, $27 \%$ as same number-DO primes, $24 \%$ as different number-PO primes, and $27 \%$ as different number-DO primes. In these 793 trials, participants produced 340 (43\%) PO completions, 162 (20\%) DO completions, and 291 (37\%) Other completions for the target fragment. The combined proportion of PO and DO target comple- 
TABLE 5

Experiment 5 Results

\begin{tabular}{lccc}
\hline & & \multicolumn{2}{c}{$\begin{array}{c}\text { Target } \\
\text { completion }\end{array}$} \\
\cline { 3 - 4 } Number & $\begin{array}{c}\text { Prime } \\
\text { completion }\end{array}$ & PO & DO \\
\hline Same & PO & .54 & .10 \\
& DO & .31 & .34 \\
Different & PO & .51 & .10 \\
& DO & .37 & .24 \\
\hline
\end{tabular}

Note. PO, prepositional object; DO, double object.

tions was comparable in each condition: $66 \%$ following same number-PO primes, $65 \%$ following same number-DO primes, $62 \%$ following different number-PO primes, and $61 \%$ following different number-DO primes. The priming manipulation did not affect the overall proportion of PO and DO target completions (all $F$ s $<1.5$ ).

Table 5 shows the proportions of PO and DO completions in the four experimental conditions. Three-way analyses of variance revealed a main effect of Target Completion $\left(F_{1}(1,27)=\right.$ $30.36, p<.01, M S_{\mathrm{e}}=.105 ; F_{2}(1,31)=16.82$, $\left.p<.01, M S_{\mathrm{e}}=.154\right)$. Table 5 shows that participants produced more PO target completions than DO target completions. The analyses of variance also revealed an interaction of Prime Completion and Target Completion $\left(F_{1}(1,27)=\right.$ $35.94, p<.01, M S_{\mathrm{e}}=.054 ; F_{2}(1,31)=30.87$, $\left.p<.01, M S_{\mathrm{e}}=.054\right)$. Table 5 shows that participants produced more target completions that were of the same type (PO or DO) as the prime completions than target completions that were of the alternative type to the prime completions. Simple effects demonstrated that participants produced more PO target completions following PO primes than following DO primes, and more DO target completions following DO primes than following PO primes (all $p \mathrm{~s}<.01$ ).

The analyses of variance revealed a weak tendency toward a three-way interaction of Prime Completion, Target Completion, and Number $\left(F_{1}(1,27)=3.43, p=.075, M S_{\mathrm{e}}=\right.$ $\left..033 ; F_{2}(1,31)=2.68, p=.11, M S_{\mathrm{e}}=.064\right)$.
Table 5 shows a somewhat larger proportion of targets of the same type as the prime when number did not vary than when number varied. However, two-way analyses of variance conducted on each level of the Number factor revealed an interaction of Prime Completion and Target Completion for both the same number level $\left(F_{1}(1,27)=31.46, p<.01, M S_{\mathrm{e}}=.048\right.$; $\left.F_{2}(1,31)=28.85, p<.01, M S_{\mathrm{e}}=.051\right)$ and the different number level $\left(F_{1}(1,27)=14.17, p<\right.$ $.01, M S_{\mathrm{e}}=.040 ; F_{2}(1,31)=5.72, p<.05, M S_{\mathrm{e}}$ $=.068)$. Hence Experiment 5 demonstrated that syntactic priming occurred when number differed between prime and target, as well as when it stayed the same. Given the findings of Experiments 3 and 4, it is unlikely that the weak tendency toward a three-way interaction is reliable, and thus we suggest that priming is unaffected by differences in number between prime and target.

\section{GENERAL DISCUSSION}

Our experiments demonstrate syntactic priming effects in written language production using a completion task. More importantly, they help clarify the conditions under which syntactic priming occurs. Thus, Experiments 1 and 2 showed that priming is stronger if the verb remains the same between prime and target, but nevertheless occurs if the verb varies. The evidence for priming when the verb varied in Experiment 1 was weaker than in Bock's experiments (e.g., Bock, 1986b), but otherwise our results suggest that written completion and spoken picture description induce comparable effects. Experiments 3, 4, and 5 showed that priming occurs when the form of the verb varies between prime and target and, moreover, strongly suggests that varying tense, aspect, or number does not affect the magnitude of priming.

Our findings are incompatible with alternative explanations. The prime and target fragments were presented as part of a list, so no discourse-level explanation is likely. The PO and DO forms are at least denotationally equivalent, so no semantic-level explanation is likely. In addition, the priming manipulation did not affect the overall proportion of the PO and DO completions in comparison to Other comple- 
tions, which were semantically disparate. The priming manipulation therefore appeared to affect the syntactic form of the target completions, but not the content of what was expressed. In particular, Experiments 1 and 3 excluded the possibility that participants were merely echoing their prime completions, either exactly or in overall lexical content, in their target completions. Nor can the effects be due to lexical priming (cf. Bock, 1989). The only possible lexical explanation relates to the repetition of the preposition to in the PO responses (cf. Levelt \& Kelter, 1982). But our results demonstrated a similar priming effect for DO responses, where there is no such repetition. Finally, Experiments 1 and 4 ruled out the possibility that priming is dependent on the repetition of a string of terminal nodes or on the repetition of syntactic structure at all levels, by demonstrating that priming occurred when prime and target differed in detailed syntactic structure. This result supports Bock and Loebell's (1990) claim that syntactic priming is not dependent on an episodic trace for the prime sentence. It also provides good evidence that the locus of syntactic priming is the choice of analysis at the level of the sentence or verb phrase.

These results provide evidence about the representation of grammatical information at the lemma stratum. They indicate that combinatorial information is, in important respects, shared, in accord with the model in Fig. 1. Experiments 1 and 2 suggest that combinatorial information is shared between verbs. However, the stronger priming effect for repeated use of the same verb suggests that the link between a verb and a combinatorial node can itself be primed. Experiments 3-5 suggest that combinatorial information is represented with respect to a featurally unspecified form of a verb. Thus it cannot constitute a property of a word-form. Moreover, we can conclude that features such as tense do not form part of a lemma node. Hence, we can conclude that combinatorial nodes link directly to featurally unspecified verb nodes, and these nodes in turn link to feature nodes. (We have no evidence about whether these feature nodes are shared or not.) Our findings argue against approaches to syn- tactic representation in which combinatorial information is represented separately for each verb (e.g., Karttunen, 1989).

Our findings also suggest that closed-class elements, such as function words and inflections, are not intrinsic to syntactic structures. If they were, different syntactic structures would be implicated in the production of past and present tense sentences, perfective and imperfective aspect sentences, and so on. Bock (1989) ascribed this position to Garrett (1982) and argued against it by showing that priming for PO structures was unaffected by differences in the identity of the preposition in the prime and target. Our results show further that differences in the inflectional elements of prime and target do not affect the magnitude of priming.

Verbs like give can be used in either the PO or the DO construction. We have assumed that these two constructions are represented by the activation of different nodes linked to give within the lemma stratum: Using the verb give with the DO construction involves activation of the $N P, N P$ node; using give with the PO construction involves activation of the NP, $P P$ node. In accord with linguistic theories, we have assumed that combinatorial information is specified over phrasal categories, such that combinatorial nodes specify the phrases that combine with the verb. Thus, the NP,NP node is activated when the verb is combined with two noun phrases; and the NP,PP node is activated when the verb is combined with a noun phrase and a prepositional phrase. Our finding that priming occurs even when the (internal) constituent structure of these phrases differs between prime and target supports this assumption.

Combinatorial nodes might encode subcategorization frames. If so, the $N P, N P$ node would be activated if and only if the verb were followed by two argument noun phrases, and the $N P, P P$ node would be activated if and only if the verb were followed by an argument noun phrase and an argument prepositional phrase. We assume that the DO construction involves two argument noun phrases, and that the PO construction involves an argument noun phrase and an argument prepositional phrase. Hence on this account, the $N P, N P$ node is activated if and 
only if a verb is used in the DO construction; and the $N P, P P$ node is activated if and only if a verb is used in the PO construction. For instance Mary gave a bone to the dog would activate the NP,PP node. However, John ate an apple near the park would not activate the NP,PP node, on the assumption that the verb eat subcategorizes for the noun phrase an apple but not for the prepositional phrase near the park.

Alternatively, combinatorial nodes might encode syntactic rules. For example, in some versions of traditional phrase-structure grammar (e.g., Chomsky, 1965), the same rule accounts for the combination of verbs with both arguments and non-arguments. For instance, the rule $\mathrm{VP} \rightarrow \mathrm{V}$ NP PP captures the structure of the verb phrase in both Mary gave a bone to the dog, where to the dog is an argument prepositional phrase, and John ate an apple near the park, where near the park is a nonargument prepositional phrase. Thus if combinatorial nodes encode overall rules of combination, and are not restricted to encoding arguments, the $N P, P P$ node would be activated in the production of both these sentences.

Our experiments do not distinguish these accounts. However, Bock and Loebell (1990) found priming between sentences that shared phrase structure but differed in subcategorization. For example, sentences like The 747 was landing by the airport's control tower, where by the airport's control tower is not a subcategorized phrase, primed sentences like The man is being stung by a bee, where by a bee is a subcategorized phrase. These results suggest that the combinatorial nodes should not be interpreted in terms of subcategorization frames, and that an interpretation of the nodes in terms of syntactic rules may be more appropriate.

\section{APPENDIX}

Experiment 1 items. The verb before the slash was used in the same verb conditions; the verb after the slash was used in the different verb conditions. The noun phrase before the slash was used in the PO-inducing conditions; the noun phrase after the slash was used in the DO-inducing conditions.
1. The racing driver showed/gave the torn overall/the helpful mechanic. The patient showed.

2. The efficient secretary handed/sent the long fax/the grumpy businessman. The little girl handed.

3. The captain gave/lent the spare lifejacket/ the old sailor. The bus driver gave.

4. The millionaire loaned/gave the valuable painting/the struggling artist. The explorer loaned.

5. The researcher sent/posted the detailed results/the experienced surgeon. The man sent.

6 . The mother gave/handed the expensive toy/the hungry baby. The air hostess gave.

7. The booking clerk posted/sold the last ticket/the young fan. The serial killer posted.

8. The fashion designer lent/showed the pink jacket/the famous journalist. The diver lent.

9. The enthusiastic child showed/gave the colourful book/the young friend. The barrister showed.

10. The grandmother handed/sent the big present/the little girl. The tennis fan handed.

11. The woman loaned/gave the rusty bike/ the new neighbour. The librarian loaned.

12. The shop assistant sold/showed the blue dress/the tall customer. The auctioneer sold.

13. The disgruntled employee sent/posted the long letter/managing director. The famous novelist sent.

14. The architect gave/handed the latest plans/the cheerful engineer. The teacher gave.

15. The blackmailer posted/sent the incriminating photos/the sleazy journalist. The lonely sailor posted.

16. The youngster showed/lent the clockwork toy/the kind teacher. The private detective showed.

17. The hostess handed/offered the dessert/ the guests. The newsagent handed.

18. The car salesman lent/sold the mini/the couple. The forest ranger lent.

19. The secretary sent/showed the invoice/ the manager. The boyfriend sent.

20. The lifeguard showed/threw the lifebelt/ the surfer. The inventor showed.

21. The swimmer loaned/gave the towel/the diver. The draftsman loaned.

22. The driving instructor gave/handed the certificate/the learner. The consultant gave. 
23. The man lent/showed the lawnmower/the neighbour. The actor lent.

24. The woman sent/posted the insurance claim/the insurance company. The fan sent.

25. The lecturer gave/lent the book/the professor. The shopkeeper gave.

26. The barman handed/offered the cocktail/ the customer. The postman handed.

27. The photographer sent/showed the prints/ the editor. The florist sent.

28. The cricket player showed/threw the ball/the umpire. The car mechanic showed.

29. The student loaned/gave the money/the friend. The little girl loaned.

30. The bank manager handed/gave the cheque/the customer. The junior surgeon handed.

31. The builder lent/showed the drill/the surveyor. The hairdresser lent.

32. The spy sent/posted the submarine blueprints/the double agent. The kidnapper sent.

Experiment 2 items. The noun phrases before the slashes were used in the PO-inducing condition; the noun phrases after the slashes were used in the DO-inducing condition.

1. The yachtsman loaned the spare lifejacket/ the angler. The happy child gave the present/the teacher. The generous girl lent.

2. The unscrupulous salesman sold the timeshare apartment/the gullible tourist. The champion cyclist showed the bicycle pump/the team manager. The tennis fan handed.

3. The pub offered a free beer/the loyal customers. The American penpal mailed a scenic postcard/the Greek woman. The injured climber showed.

4. The messenger handed the unsigned note/ the countess. The senior lecturer loaned the main textbook/the visiting professor. The head waiter gave.

5. The ambulanceman offered the steaming hot drink/the shivering accident victim. The disgruntled employee wrote a letter of complaint/ the managing director. The spotty apprentice offered.

6. The structural engineer gave the detailed report/the solicitor. The waiter offered the bub- bling champagne/the celebrating couple. The ambassador lent.

7. The thoughtful friend loaned some money/the impoverished student. The kind landlord rented the small cottage/the homeless family. The research assistant sent.

8. The footman served the roast potatoes/the dinner guest. The doting mother gave the expensive toy car/the baby. The medical researcher sent.

9. The lonely sailor wrote a long letter/his girlfriend. The polite man passed the salt/the other customer. The estate agent showed.

10. The enthusiastic youngster showed the book/a friend. The angry voter sent a vitriolic letter/the politician. The art historian loaned.

11. The booking clerk mailed the concert tickets/the anxious customer. The barman offered the cocktail/the depressed customer. The driving examiner handed.

12. The lifeguard threw the long rope/the drowning child. The blackmailer posted the incriminating letter/the Tory M.P. The hostess gave.

Experiments 3 and 4 items. Three forms of the verb are separated by two slashes. The first was used in the same conditions in both Experiments 3 and 4; the second was used in the different tense conditions of Experiment 3; the third was used in the different aspect conditions of Experiment 4. The noun phrase before the slash was used in the PO-inducing conditions; the noun phrase after the slash was used in the DO-inducing conditions.

1. The racing driver showed/shows/was showing the torn overall/the helpful mechanic. The patient showed.

2. The efficient secretary handed/hands/was handing the long fax/the grumpy businessman. The little girl handed.

3. The captain gave/gives/was giving the spare lifejacket. The bus driver gave.

4. The millionaire loaned/loans/was loaning the valuable painting/the struggling artist. The explorer loaned.

5. The researcher sent/sends/was sending the detailed results/the experienced surgeon. The man sent. 
6. The mother gave/gives/was giving the expensive toy/the hungry baby. The air hostess gave.

7. The booking clerk posted/posts/was posting the last ticket/the young fan. The serial killer posted.

8. The fashion designer lent/lends/was lending the pink jacket/the famous journalist. The diver lent.

9. The enthusiastic child showed/shows/was showing the colourful book/the young friend. The barrister showed.

10. The grandmother handed/hands/was handing the big present/the little girl. The tennis fan handed.

11. The woman loaned/loans/was loaning the rusty bike/the new neighbour. The librarian loaned.

12. The shop assistant sold/sells/was selling the blue dress/the tall customer. The auctioneer sold.

13. The disgruntled employee sent/sends/ was sending the long letter/the managing director. The famous novelist sent.

14. The architect gave/gives/was giving the latest plans/the cheerful engineer. The teacher gave.

15. The blackmailer posted/posts/was posting the incriminating photos/the sleazy journalist. The lonely sailor posted.

16. The youngster showed/shows/was showing the clockwork toy/the kind teacher. The private detective showed.

17. The hostess handed/hands/was handing the dessert/the guests. The newsagent handed.

18. The car salesman lent/lends/was lending the mini/the couple. The forest ranger lent.

19. The secretary posted/posts/was posting the invoice/the manager. The boyfriend posted.

20. The lifeguard showed/shows/was showing the lifebelt/the surfer. The inventor showed.

21. The swimmer loaned/loans/was loaning the towel/the diver. The draftsman loaned.

22. The driving instructor gave/gives/was giving the certificate/the learner. The consultant gave.

23. The man lent/lends/was lending the lawnmower/the neighbour. The actor lent.

24. The woman sent/sends/was sending the insurance claim/the insurance company. The fan sent.
25. The lecturer gave/gives/was giving the book/the professor. The shopkeeper gave.

26. The barman handed/hands/was handing the cocktail/the customer. The postman handed.

27. The photographer sent/sends/was sending the prints/the editor. The florist sent.

28. The cricket player showed/shows/was showing the ball/the umpire. The car mechanic showed.

29. The student loaned/loans/was loaning the money/the friend. The little girl loaned.

30. The bank manager handed/hands/was handing the cheque/the customer. The junior surgeon handed.

31. The builder lent/lends/was lending the drill/the surveyor. The hairdresser lent.

32. The spy sent/sends/was sending the submarine blueprints/the double agent. The kidnapper sent.

Experiment 5 items. The singular conditions used the form of the preverbal head noun before the slash and the form of the verb before the slash; the plural conditions used the form of the preverbal head noun after the slash and the form of the verb after the slash. The postverbal noun phrase before the slash was used in the PO-inducing conditions; the postverbal noun phrase after the slash was used in the DO-inducing conditions.

1. The racing driver/drivers shows/show the torn overall/the helpful mechanic. The patient shows.

2. The youngster/youngsters shows/show the toy/the teacher. The private detective shows.

3. The lifeguard/lifeguards shows/show the lifebelt/surfer. The inventor shows.

4. The cricket player/players shows/show the ball/the umpire. The car mechanic shows.

5. The efficient assistant/assistants hands/ hand the long faxes/the grumpy businessman. The little girl hands.

6. The grandparent/grandparents hands/hand the big present/the little girl. The tennis fan hands.

7. The hostess/hostesses hands/hand the dessert/the guests. The newsagent hands.

8. The bank manager/managers hands/hand the money/the customer. The junior surgeon hands. 
9. The steward/stewards gives/give the spare lifejacket/the old sailor. The bus driver gives.

10. The teenager/teenagers gives/give the expensive toy/the hungry baby. The air hostess gives.

11. The architect/architects gives/give the latest plans/the cheerful engineer. The teacher gives.

12. The lecturer/lecturers gives/give the book/the professor. The shopkeeper gives.

13. The millionaire/millionaires loans/loan the valuable painting/the struggling artist. The explorer loans.

14. The swimmer/swimmers loans/loan the towel/the diver. The draftsman loans.

15. The woman/women loans/loan the rusty bike/the new neighbour. The librarian loans.

16. The booking clerk/clerks posts/post the last ticket/the young fan. The serial killer posts.

17. The blackmailer/blackmailers posts/post the incriminating photos/the sleazy journalist. The lonely sailor posts.

18. The car salesman/salesmen lends/lend the mini/the couple. The forest ranger lends.

19. The man/men lends/lend the lawnmower/the neighbour. The actress lends.

20. The fashion designer/designers lends/ lend the pink jacket/the famous journalist. The diver lends.

21. The builder/builders lends/lend the drill/ the surveyor. The hairdresser lends.

22. The disgruntled employee/employees sends/send the long letter/the managing director. The famous novelist sends.

23. The secretary/secretaries sends/send the invoice/the manager. The boyfriend sends.

24. The woman/women sends/send the insurance claim/the insurance company. The fan sends.

25. The nurse/nurses shows/show the X-ray/ the doctor. The jeweller shows.

26. The courier/couriers hands/hand the parcel/the receptionist. The child hands.

27. The librarian/librarians sends/send the reminder/the student. The thoughtful granddaughter sends.

28. The young woman/women loans/loan the necklace/the teenager. The motorist loans.

29. The researcher/researchers posts/post the detailed questionnaire/the eager journalist. The personnel manager posts.
30. The spy/spies sells/sell the stolen documents/the foreign diplomat. The shop assistant sells.

31. The florist/florists gives/give the huge bouquet/the startled butler. The pharmacist gives.

32. The receptionist/receptionist lends/lend the spare key/the busy assistant. The coastguard lends.

\section{REFERENCES}

Badecker, W., Miozzo, M., \& Zanuttini, R. (1995). The two-stage model of lexical retrieval: Evidence from a case of anomia with a selective preservation of grammatical gender. Cognition, 57, 193-216.

Bock, J. K. (1986a). Meaning, sound, and syntax: Lexical priming in language production. Journal of Experimental Psychology: Learning, Memory, and Cognition, 12, 575-586.

Bock, J. K. (1986b). Syntactic persistence in language production. Cognitive Psychology, 18, 355-387.

Bock, J. K. (1989). Closed class immanence in sentence production. Cognition, 31, 163-186.

Bock, J. K., \& Loebell, H. (1990). Framing sentences. Cognition, 35, 1-39.

Bock, J. K., Loebell, H., \& Morey (1992). From conceptual roles to structural relations: Bridging the syntactic cleft. Psychological Review, 99, 150-171.

Branigan, H. P., Pickering, M. J., Liversedge, S. P., Stewart, A. J., \& Urbach, T. P. (1995). Syntactic priming: Investigating the mental representation of language. Journal of Psycholinguistic Research, 24, 489-506.

Brown, R., \& McNeill, D. (1966). The "tip-of-the-tongue" phenomenon. Journal of Verbal Learning and Verbal Behavior, 5, 325-337.

Butterworth, B. (1989). Lexical access in speech production. In W.D. Marslen-Wilson (Ed.), Lexical representation and process (pp. 108-135). Cambridge, MA: MIT Press.

Caramazza, A., \& Miozzo, M. (1997). The relation between syntactic and phonological knowledge in lexical access: Evidence from the "tip-of-the-tongue" phenomenon. Cognition, 64, 309-343.

Chomsky, N. (1965). Aspects of the theory of syntax. Cambridge, MA: MIT Press.

Chomsky, N. (1981). Lectures on government and binding. Dordrecht, The Netherlands: Foris.

Dell, G. S. (1986). A spreading activation model of retrieval in sentence production. Psychological Review, 93, 283-321.

Estival, D. (1985). Syntactic priming of the passive in English. Text, 5, 7-21.

Fodor, J. A., Garrett, M. F., Walker, E. C. T., \& Parkes, C. H. (1980). Against definitions. Cognition, 8, 263367. 
Fromkin, V. A. (1971). The non-anomalous nature of anomalous utterances. Language, 47, 27-52.

Garrett, M. F. (1975). The analysis of sentence production. In G. H. Bower (Ed.), The Psychology of Learning and Motivation (pp. 133-177). New York: Academic Press.

Garrett, M. (1980). Levels of processing in speech production. In B. Butterworth (Ed.), Language production (Vol. 1, pp. 177-220). London: Academic Press.

Garrett, M. F. (1982). Production of speech: Observations from normal and pathological language use. In A. W. Ellis (Ed.), Normality and pathology in cognitive functions (pp. 19-76). London: Academic Press.

Giles, H. \& Powesland, P. (1975). Speech style and social evaluation. London: Academic Press.

Jackendoff, R. (1990). Semantic structures. Cambridge, MA: MIT Press.

Jescheniak, J. D., \& Levelt, W. J. M. (1994). Word frequency effects in speech production - retrieval of syntactic information and of phonological form. Journal of Experimental Psychology: Learning, Memory, and Cognition, 20, 824-843.

Karttunen, L. (1989). Radical lexicalism. In M. Baltin \& A. Kroch (Eds.), Alternative conceptions of phrase structure. Chicago: University of Chicago Press.

Kempen, G., \& Huijbers, P. (1983). The lexicalization process in sentence production and naming: Indirect election of words. Cognition, 14, 185-209.

Levelt, W. J. M. (1989). Speaking: From intention to articulation. Cambridge, MA: MIT Press.

Levelt, W., \& Kelter, S. (1982). Surface form and memory in question answering. Cognitive Psychology, 14, 78-106.

Levelt, W. J. M., Schriefers, H., Vorberg, D., Meyer, A. S., Pechmann, T., \& Havinga, J. (1991). The time course of lexical access in speech production: A study of picture naming. Psychological Review, 98, 122-142.
Meyer. A. S., \& Bock, J. K. (1992). The tip-of-the-tongue phenomenon - blocking or partial activation. Memory \& Cognition, 20, 715-726.

Pollard, C., \& Sag, I. A. (1987). Information-based syntax and semantics (Vol. 1). Stanford, CA: CSLI.

Pollard, C., \& Sag, I. A. (1994) Head-driven phrase structure grammar. Stanford, CA \& Chicago, IL: CSLI \& University of Chicago Press.

Potter, M. C., \& Lombardi, L. (1998). Syntactic priming in immediate recall of sentences. Journal of Memory and Language, 38, 265-282.

Roelofs, A. (1992). A spreading-activation theory of lemma retrieval in speaking. Cognition, 42, 107-142.

Roelofs, A. (1993). Testing a non-decompositional theory of lemma retrieval in speaking: Retrieval of verbs. Cognition, 47, 59-87.

Schenkein, J. (1980). A taxonomy for repeating action sequences in natural conversation. In B. Butterworth (Ed.), Language production (Vol. 1, pp. 21-47). London: Academic Press.

Schriefers, H., Meyer, A. S., \& Levelt, W. J. M. (1990). Exploring the time course of lexical access in production: Picture-word interference studies. Journal of Memory and Language, 29, 86-102.

Tannen, D. (1989). Talking voices: Repetition, dialogue and imagery in conversational discourse. Cambridge: Cambridge University Press.

Vigliocco, G., Garrett, M. F., \& Antonini, T. (1997). Grammatical gender is on the tip of Italian tongues. Psychological Science, 8, 314-317.

Weiner, E. J., \& Labov, W. (1983). Constraints on the agentless passive. Journal of Linguistics, 19, 29-58.

(Received October 20, 1997)

(Revision received May 19, 1998) 